\title{
Diagnosis, Evaluation, and Management of the Hypertensive Disorders of Pregnancy: Executive Summary
}

\begin{abstract}
The guideline summarized here has been prepared by the Canadian Hypertensive Disorders of Pregnancy Working Group, reviewed and approved by the Hypertension Guideline Committee, reviewed by the Maternal Fetal Medicine and Family Physician Advisory committees, and approved by the Executive and Council of the Society of Obstetricians and Gynaecologists of Canada.
\end{abstract}

\section{PRINCIPAL AUTHORS \\ Laura A. Magee, MD, Vancouver BC \\ Anouk Pels, MSc, Amsterdam, the Netherlands \\ Michael Helewa, MD, Winnipeg MB \\ Evelyne Rey, MD, Montreal QC \\ Peter von Dadelszen, MBChB, Vancouver BC}

\author{
HYPERTENSION GUIDELINE COMMITTEE \\ Laura A. Magee, MD (Chair), Vancouver BC \\ Francois Audibert, MD, Montreal QC \\ Emmanuel Bujold, MD, Quebec QC \\ Anne-Marie Côté, MD, Sherbrooke QC \\ Myrtle Joanne Douglas, MD, Vancouver BC \\ Genevieve Eastabrook, MD, FRCSC, London ON \\ Tabassum Firoz, MD, Vancouver BC \\ Paul Gibson, MD, Calgary AB \\ Andrée Gruslin, MD, Ottawa ON \\ Jennifer Hutcheon, PhD, Vancouver BC \\ Gideon Koren, MD, Toronto ON \\ lan Lange, MD, Calgary $A B$ \\ Line Leduc, MD, Montreal QC \\ Alexander G. Logan, MD, Toronto ON
}

Key Words: Hypertension, blood pressure, pregnancy, preeclampsia, maternal outcome, perinatal outcome, long-term prognosis
Karen L. MacDonell, PhD, Vancouver BC

Jean-Marie Moutquin, MD, Sherbrooke QC

Ilana Sebbag, MD, Vancouver BC

Disclosure statements have been received from all members of the committee.

The literature searches and bibliographic support for this guideline were undertaken by Becky Skidmore, Medical Research Analyst, Society of Obstetricians and Gynaecologists of Canada.

\section{Abstract}

Objective: This executive summary presents in brief the current evidence assessed in the clinical practice guideline prepared by the Canadian Hypertensive Disorders of Pregnancy Working Group and published by Pregnancy Hypertension

(http://www.pregnancyhypertension.org/article/S2210-

$7789(14) 00004-X / f u l l t e x t)$ to provide a reasonable approach to the diagnosis, evaluation, and treatment of the hypertensive disorders of pregnancy.

Evidence: Published literature was retrieved through searches of Medline, CINAHL, and The Cochrane Library in March 2012 using appropriate controlled vocabulary (e.g., pregnancy, hypertension, pre-eclampsia, pregnancy toxemias) and key words (e.g., diagnosis, evaluation, classification, prediction, prevention, prognosis, treatment, postpartum follow-up). Results were restricted to systematic reviews, randomized control trials, controlled clinical trials, and observational studies published in French or English between January 2006 and February 2012. Searches were updated on a regular basis and incorporated in the guideline to September 2013. Grey (unpublished) literature was identified through searching the websites of health technology assessment and health technology-related agencies, clinical practice guideline collections, clinical trial registries, and national and international medical specialty societies.

Values: The quality of evidence in the guideline summarized here was rated using the criteria described in the Report of the Canadian Task Force on Preventative Health Care (Table 1).

J Obstet Gynaecol Can 2014;36(5):416-438

This document reflects emerging clinical and scientific advances on the date issued and is subject to change. The information should not be construed as dictating an exclusive course of treatment or procedure to be followed. Local institutions can dictate amendments to these opinions. They should be well documented if modified at the local level. None of these contents may be reproduced in any form without prior written permission of the SOGC. 
Table 1. Key to evidence statements and grading of recommendations, using the ranking of the Canadian Task Force on Preventive Health Care

\begin{tabular}{|c|c|c|}
\hline \multicolumn{2}{|c|}{ Quality of evidence assessment* } & \multirow{2}{*}{$\begin{array}{l}\text { Classification of recommendations } \dagger \\
\text { A. There is good evidence to recommend the clinical preventive action }\end{array}$} \\
\hline I: & $\begin{array}{l}\text { Evidence obtained from at least one properly randomized } \\
\text { controlled trial }\end{array}$ & \\
\hline II-2: & $\begin{array}{l}\text { Evidence from well-designed cohort (prospective or } \\
\text { retrospective) or case-control studies, preferably from } \\
\text { more than one centre or research group }\end{array}$ & $\begin{array}{l}\text { C. The existing evidence is conflicting and does not allow to make a } \\
\text { recommendation for or against use of the clinical preventive action; } \\
\text { however, other factors may influence decision-making }\end{array}$ \\
\hline III: & $\begin{array}{l}\text { Opinions of respected authorities, based on clinical experience, } \\
\text { descriptive studies, or reports of expert committees }\end{array}$ & $\begin{array}{l}\text { L. There is insufficient evidence (in quantity or quality) to make } \\
\text { a recommendation; however, other factors may influence } \\
\text { decision-making }\end{array}$ \\
\hline
\end{tabular}

*The quality of evidence reported in these guidelines has been adapted from The Evaluation of Evidence criteria described in the Canadian Task Force on Preventive Health Care. ${ }^{39}$

†Recommendations included in these guidelines have been adapted from the Classification of Recommendations criteria described in the Canadian Task Force on Preventive Health Care. ${ }^{39}$

\section{RECOMMENDATIONS}

\section{CHAPTER 1:}

DIAGNOSIS AND CLASSIFICATION OF THE MEASUREMENT OF BP FOR HDPS

- BP Measurement: 1-10

- Diagnosis of Hypertension: 11-17

- Measurement of Proteinuria: 18-24

- Classification of HDPs: 25-31

- Investigations to Classify HDPs: $32-37$

\section{CHAPTER 2:}

\section{PREDICTION AND PREVENTION}

- Predicting Preeclampsia: $38-40$

- Preventing Preeclampsia and its Complications in Women at Low Risk: $41-46$

- Preventing Preeclampsia and its Complications in Women at Increased Risk: 47-54

\section{CHAPTER 3:}

\section{TREATMENT OF THE HDPs}

- Dietary and Lifestyle Changes: 55-59

- Place of Care: 60,61

\section{ABBREVIATIONS}

BP blood pressure

HDP hypertensive disorder of pregnancy

HELLP hemolysis, elevated liver enzymes, low platelets

IUGR intrauterine growth restriction

NICU neonatal intensive care unit

$\mathrm{RCT}$ randomized control trial

RDS respiratory distress syndrome
- Antihypertensive Therapy for Severe Hypertension: 62-68

- Antihypertensive Therapy for Non-Severe Hypertension Without Comorbid Conditions: 69-73

- For Non-Severe Hypertension (BP of 140-159/ 90-109 mmHg) With Comorbid Conditions: 74-76

- Corticosteroids for Acceleration of Fetal Pulmonary Maturity: $77-80$

- Timing of Delivery for Women With Preeclampsia: 81-88

- Timing of Delivery for Women With Gestational Hypertension: 89,90

- Timing of Delivery for Women with Pre-existing Hypertension: 91

- Mode of Delivery: 92-97

- Anaesthesia: General Principles: 98-101

- Anaesthesia: Fluid Administration: 102-105

- Monitoring: 106-108

- Coagulation: 109, 110

- Aspects of Care Specific to Women Wth Pre-Existing Hypertension: 111-115

- Aspects of Care for Women With Preeclampsia: Magnesium Sulphate for Preventing or Treating Eclampsia: 116-123

- Aspects of Care for Women With Preeclampsia: Plasma Volume Expansion: 124

- Therapies for HELLP Syndrome: 125-131

- Care in the 6 Weeks Postpartum: 132-142

- Care Beyond 6 Weeks Postpartum: 143-148

- Effects of Maternal Hypertension and its Therapies on Child Neurobehavioural Development: 149, 150

\section{CHAPTER 4:}

PATIENT PERSPECTIVE: 151-153 


\section{INTRODUCTION}

$\mathrm{H}$ ypertensive disorders of pregnancy remain leading causes of maternal and perinatal morbidity and mortality. ${ }^{1,2}$ The guideline summarized here assesses the quality of the relevant existing evidence and provides a reasonable approach to the diagnosis, evaluation, and treatment of the HDP, focusing on Canadian context.

Our purpose is to support evidence-based maternity care of women who are planning pregnancy and are at risk of an HDP, have an HDP in the current pregnancy, or are postpartum and had an HDP. When necessary, we have provided expert opinion about reasonable clinical care. Our health intent and aim is to improve short- and longterm maternal, perinatal, and paediatric outcomes and the cost-effectiveness of related interventions in pregnancies complicated by an HDP. The expected benefit of this guideline is improved outcomes for mother, baby, and child through evidence-advised practice. Our target users are multidisciplinary maternity care providers from primary to tertiary levels of health care.

The questions that this guideline seeks to address are:

- How, and in what setting, should BP be measured in pregnancy, and what is an abnormal BP?

- How should proteinuria be measured in pregnancy? What constitutes significant proteinuria? Is heavy proteinuria an indication for delivery?

- How should the HDPs be diagnosed and classified? What constitutes severe preeclampsia?

- What are the prognoses of pregnancies complicated by pre-existing hypertension, gestational hypertension, or preeclampsia?

- How can preeclampsia and its complications be predicted and/or prevented by lifestyle changes, medication, and/or care of a specific type or in a specific location?

- How should women with an HDP be managed regarding initial investigations, dietary and lifestyle changes, place of care, antihypertensive therapy, aspects of care specific to women with preeclampsia (such as magnesium sulphate), mode and timing of delivery, intrapartum care (including BP monitoring and analgesia/anaesthesia), and postpartum monitoring, treatment, and counselling regarding the impact of an HDP on both future pregnancy outcomes and longterm maternal and paediatric outcomes?

- What is the patient's perspective on her diagnosis and evaluation?
- How can this guideline be implemented into clinical practice?

This document presents a summary of the recommendations, along with supporting text for the new classification of the HDPs, and all of the tables provided in the full guideline. Because of the breadth of the topic and the volume of material covered, the methods, supporting text for all recommendations, and the full list of references, including those for the tables, have been published separately as an open-access article in Pregnancy Hypertension. ${ }^{3}$

Important changes affect all aspects of care covered in the 2008 guidelines. Notable examples include the addition of systolic BP in the definition of pregnancy hypertension, revised HDP classification, new information on prevention, more direction with respect to timing of delivery in women with any HDP, information about magnesium sulphate for fetal neuroprotection at $<32$ weeks, a new gestational age cut-off $(\leq 34+6$ instead of $\leq 33+6$ weeks) for administration of steroids, and a section on knowledge translation with links to useful tools for women and practitioners.

\section{CHAPTER 1: \\ DIAGNOSIS OF HDP AND CLASSIFICATION OF BP MEASUREMENTS}

\section{BP Measurement}

\section{Recommendations}

1. Blood pressure should be measured with the woman in the sitting position with the arm at the level of the heart. (II-2A)

2. An appropriately sized cuff (i.e., length 1.5 times the circumference of the arm) should be used. (II-2A)

3. Korotkoff phase $\mathrm{V}$ should be used to designate diastolic blood pressure. (I-A)

4. If blood pressure is consistently higher in one arm, the arm with the higher values should be used for all blood pressure measurements. (III-B)

5. Blood pressure can be measured using a mercury sphygmomanometer, a calibrated aneroid device, or an automated blood pressure machine that has been validated for use in preeclampsia. (II-2A)

6. Automated blood pressure machines that have not been validated for use in women with preeclampsia may underestimate or overestimate blood pressure in those women; a comparison of readings using mercury sphygmomanometry or a calibrated aneroid device is recommended. (II-2A) 
7. In the office setting, when blood pressure elevation is non-severe and preeclampsia is not suspected, ambulatory blood pressure monitoring or home blood pressure monitoring is useful to confirm persistently elevated blood pressure. (II-2C)

8. When home blood pressure monitoring is used, maternity care providers should ensure that patients have adequate training in measuring their blood pressure and interpreting the readings. (III-C)

9. The accuracy of all blood pressure measurement devices used in hospitals or offices should be checked regularly against a calibrated device. (II-3C)

10. The accuracy of all automated devices used for home blood pressure monitoring should be checked regularly against a calibrated device. (III-C)

\section{Diagnosis of Hypertension}

\section{Recommendations}

11. The diagnosis of hypertension should be based on office or in-hospital blood pressure measurements. (II-B)

12. Hypertension in pregnancy should be defined as an office (or in-hospital) systolic blood pressure $\geq 140 \mathrm{mmHg}$ and/or diastolic blood pressure $\geq 90 \mathrm{mmHg}$, based on the average of at least 2 measurements, taken at least 15 minutes apart, using the same arm. (II-2B)

13. Resistant hypertension should be defined as the need for 3 antihypertensive medications for blood pressure control at $\geq 20$ weeks' gestation. (III-C)

14. A transient hypertensive effect should be defined as an office systolic blood pressure $\geq 140 \mathrm{mmHg}$ or a diastolic blood pressure $\geq 90 \mathrm{mmHg}$ that is not confirmed after rest, on repeat measurement, on the same or on subsequent visits. (II-2B)

15. A white-coat hypertensive effect refers to blood pressure that is elevated in the office (i.e., systolic $\geq 140 \mathrm{mmHg}$ or diastolic $\geq 90 \mathrm{mmHg}$ ), but $<135 \mathrm{mmHg}$ (systolic) and $<85 \mathrm{mmHg}$ (diastolic) on ambulatory or home blood pressure monitoring. (II-2B)

16. A masked hypertensive effect refers to blood pressure that is normal in the office (i.e., systolic $<140 \mathrm{mmHg}$ and diastolic $<90 \mathrm{mmHg}$ ) but elevated on ambulatory or home blood pressure monitoring (i.e., systolic $\geq 135 \mathrm{mmHg}$ or diastolic $\geq 85 \mathrm{mmHg}$ ). (II-2B)

17. Severe hypertension should be defined, in any setting, as a systolic blood pressure of $\geq 160 \mathrm{mmHg}$ or a diastolic blood pressure of $\geq 110 \mathrm{mmHg}$ based on the average of at least 2 measurements, taken at least 15 minutes apart, using the same arm. (II-2B)

\section{Measurement of Proteinuria}

\section{Recommendations}

18. All pregnant women should be assessed for proteinuria. (II-2B)

19. Urinary dipstick testing (by visual or automated testing) may be used for screening for proteinuria when the suspicion of preeclampsia is low. (II-2B)

20. Significant proteinuria should be defined as $\geq 0.3 \mathrm{~g} / \mathrm{d}$ in a complete 24 -hour urine collection or $\geq 30 \mathrm{mg} / \mathrm{mmol}$ urinary creatinine in a spot (random) urine sample. (II-2B)

21. Significant proteinuria should be suspected when urinary dipstick proteinuria is $\geq 1+$. (II-2A)

22. More definitive testing for proteinuria (by urinary protein:creatinine ratio or 24-hour urine collection) is encouraged when there is a suspicion of preeclampsia, including: $\geq 1+$ dipstick proteinuria in women with hypertension and risingblood pressure and in women withnormal blood pressure, but symptoms or signs suggestive of preeclampsia. (II-2A)

23. Proteinuria testing does not need to be repeated once significant proteinuria of preeclampsia has been confirmed. (II-2A)

24. There is insufficient information to make a recommendation about the accuracy of the urinary albumin:creatinine ratio. (II-2L)

\section{Classification of HDPs}

\section{Recommendations}

25. Hypertensive disorders of pregnancy should be classified as pre-existing hypertension, gestational hypertension, preeclampsia, or "other hypertensive effects" on the basis of different diagnostic and therapeutic considerations. (II-2B) (Table 2)

26. The presence or absence of preeclampsia must be ascertained, given its clear association with more adverse maternal and perinatal outcomes. (II-2B)

27. In women with pre-existing hypertension, preeclampsia should be defined as resistant hypertension, new or worsening proteinuria, one or more adverse conditions, or one or more severe complications. (II-2B)

28. In women with gestational hypertension, preeclampsia should be defined as new-onset proteinuria, one or more adverse conditions, or one or more severe complications. (II-2B)

29. Severe preeclampsia should be defined as preeclampsia complicated by one or more severe complications. (II-2B) 


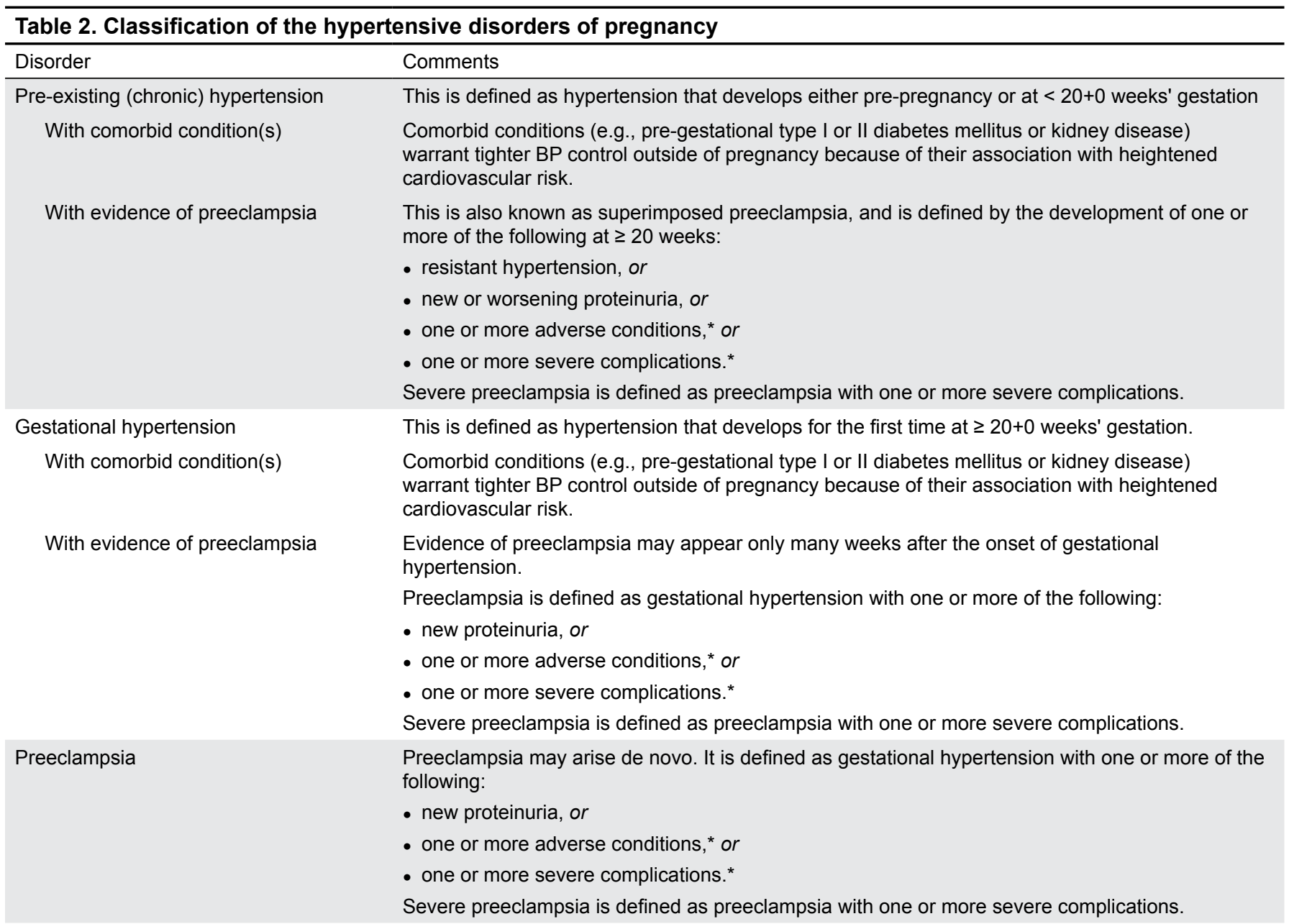

Other hypertensive effects $\dagger$

Transient hypertensive effect

White-coat hypertensive effect

Masked hypertensive effect
Elevated BP may be due to environmental stimuli, e.g., the pain of labour.

This is defined as BP that is elevated in the office (sBP $\geq 140 \mathrm{mmHg}$ or $\mathrm{dBP} \geq 90 \mathrm{mmHg}$ ), but consistently normal outside of the office $(<135 / 85 \mathrm{mmHg}$ ) by ABPM or HBPM

This is defined as BP that is consistently normal in the office $(\mathrm{sBP}<140 \mathrm{mmHg}$ or $\mathrm{dBP}$ $<90 \mathrm{mmHg}$ ), but elevated outside of the office $(\geq 135 / 85 \mathrm{mmHg}$ ) by ABPM or repeated HBPM.

sBP: systolic BP; dBP diastolic BP; ABPM: ambulatory BP monitoring; HBPM: home BP monitoring

*Adverse conditions and severe complications of preeclampsia are defined in Table 3.

†These may occur in women whose BP is elevated at $<20+0$ or $\geq 20+0$ weeks who are suspected of having pre-existing or gestational hypertension/ preeclampsia, respectively.

30. Severe preeclampsia, as defined in this guideline, warrants delivery. (II-2B)

31. The term PIH (pregnancy-induced hypertension) should be abandoned, as its meaning in clinical practice is unclear. (III-D)

\section{Definition of Preeclampsia}

Preeclampsia is most commonly defined by new-onset proteinuria and, potentially, other end-organ dysfunction. Hypertension and proteinuria are discussed above under "Diagnosis of Hypertension"” and "Management of Proteinuria." Women with preeclampsia may have a diminished, or no, nocturnal BP decrease. ${ }^{4}$ Maternal end-organ dysfunction and fetal manifestations of preeclampsia illustrated in the Figure are all non-specific. In this model of its origins we describe preeclampsia that arises primarily through imperfect placentation (earlyonset or "placental" preeclampsia [pink]) or through either a lowered maternal threshold or excessive physiological placentation (late-onset or "maternal" preeclampsia [blue]). Some aspects of the preeclampsia process are specific to it, while others are shared with normotensive IUGR. A lowered maternal threshold may also influence the development of early-onset preeclampsia through 


\section{The origins and consequences of preeclampsia}

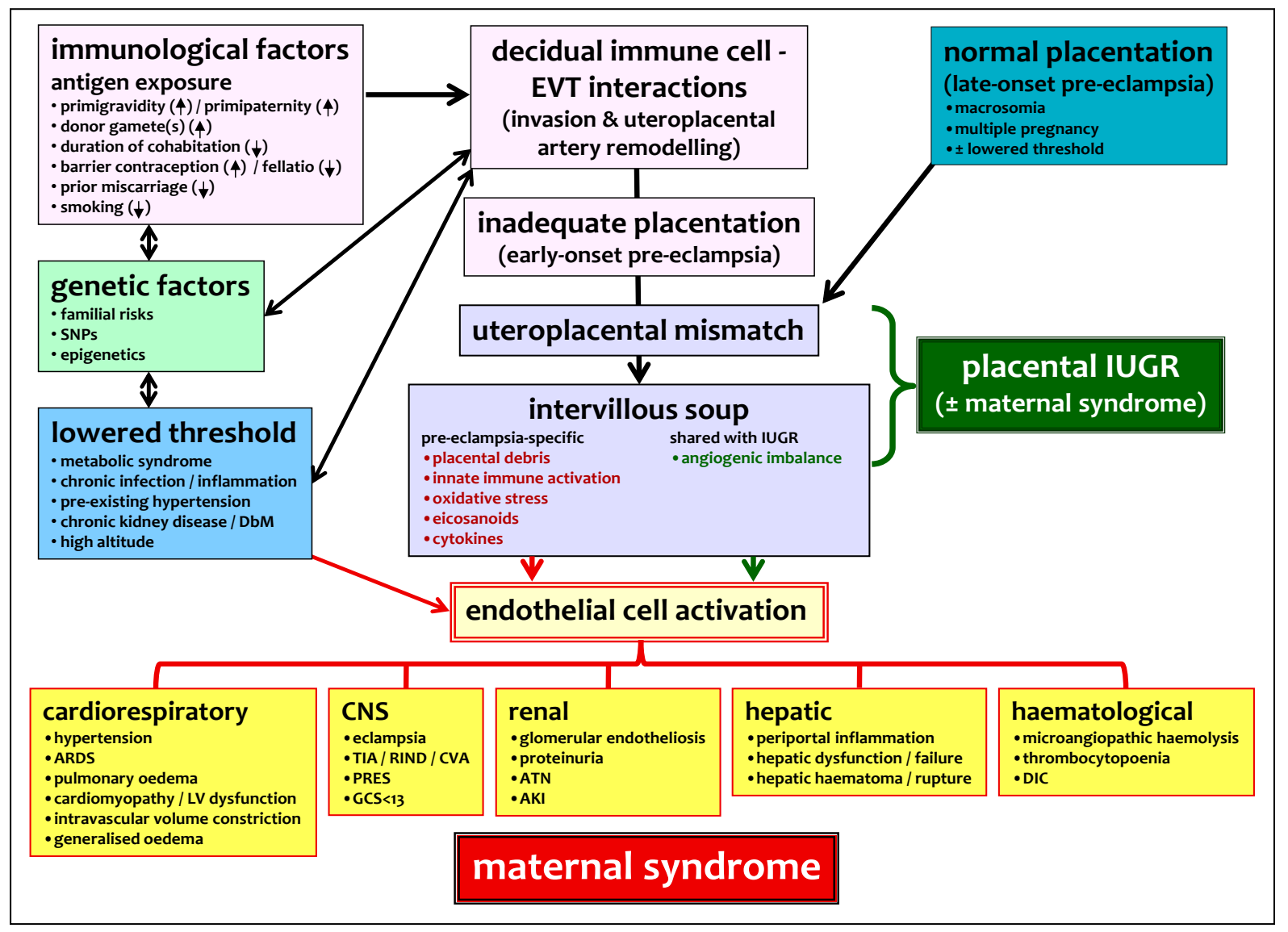

EVT: extravillous trophoblast; SNP: single nucleotide polymorphism; ARDS: acute respiratory distress syndrome; CNS: central nervous system; TIA: transient ischemic attack; RIND: reversible ischemic neurological deficit; CVA: cerebrovascular accident; PRES: posterior reversible encephalopathy syndrome; GCS: Glasgow Coma Scale; ATN: acute tubular necrosis; AKI: acute kidney injury; DIC: disseminated intravascular coagulation; DbM: diabetes mellitus; LV: left ventricle

direct endothelial cell activation. The consequences of endothelial cell activation that appear consistent between all women with preeclampsia include a variable impact on multiple vulnerable organ systems. Disease severity generally correlates with the degree and number of organ dysfunctions. Fetal manifestations may occur before, with, or in the absence of maternal manifestations. ${ }^{5}$

Table 3 outlines the end-organ dysfunctions of preeclampsia: adverse conditions and severe complications. Adverse conditions consist of maternal symptoms, signs, and abnormal laboratory results, and abnormal fetal monitoring results that may herald the development of severe maternal or fetal complications (including stillbirth). The adverse conditions are those that we wait for and respond to (e.g., low oxygen saturation) in an effort to avoid entirely the severe complications (e.g., pulmonary edema). That response could be more intensive maternal or fetal monitoring, specific treatment, or delivery. Severe maternal complications of preeclampsia warrant delivery.
The adverse conditions are manifestations of preeclampsia that increase the risk of adverse maternal or perinatal outcomes. ${ }^{6}$ Table 3 lists the adverse conditions by maternal organ system. Of particular importance are preterm preeclampsia, chest pain or dyspnea, and abnormality of one or more of oxygen saturation by pulse oximetry, platelet count, serum creatinine, or aspartate transaminase. ${ }^{6}$ Proteinuria predicts neither short-term adverse outcomes nor long-term maternal renal prognosis. ${ }^{7,8}$ HELLP syndrome is represented by its component parts (hemolysis, elevated liver enzymes, and low platelets), to which we react to by initiating delivery.

How maternal adverse conditions may predict fetal or neonatal outcomes in preeclampsia is unclear. The perinatal literature suggests that abnormal fetal monitoring of various types may identify increased fetal risk. The biophysical profile has unproven utility in high risk women, ${ }^{9,10}$ and may falsely reassure with early-onset IUGR ${ }^{11}$ or preeclampsia. ${ }^{12}$

Currently, there is no single fetal monitoring test to accurately predict fetal compromise in women with 


\begin{tabular}{|c|c|c|}
\hline Organ system affected & $\begin{array}{l}\text { Adverse conditions } \\
\text { (that increase the risk of severe complications) }\end{array}$ & $\begin{array}{l}\text { Severe complications } \\
\text { (that warrant delivery) }\end{array}$ \\
\hline \multirow{3}{*}{ Central nervous system } & \multirow{3}{*}{ Headache/visual symptoms } & PRES \\
\hline & & Cortical blindness or retinal detachment \\
\hline & & Glasgow coma scale $<13$ \\
\hline \multirow[t]{4}{*}{ Cardiorespiratory } & \multirow{4}{*}{$\begin{array}{l}\text { Chest pain/dyspnea } \\
\text { Oxygen saturation }<97 \%\end{array}$} & Uncontrolled severe hypertension (over a period of $12 \mathrm{~h}$ \\
\hline & & despite use of three antihypertensive agents) \\
\hline & & $\begin{array}{l}\text { Oxygen saturation }<90 \% \text {, need for } \geq 50 \% \text { oxygen for } \\
>1 \mathrm{~h} \text {, intubation (other than for Caesarean section), } \\
\text { pulmonary edema }\end{array}$ \\
\hline & & Positive inotropic support \\
\hline Haematological & Low platelet count & \\
\hline \multirow[t]{3}{*}{ Renal } & Elevated serum creatinine & Acute kidney injury (creatinine $>150 \mu \mathrm{M}$ with no prior \\
\hline & Elevated serum uric acid & renal disease) \\
\hline & & New indication for dialysis \\
\hline \multirow[t]{4}{*}{ Hepatic } & Nausea or vomiting & Hepatic dysfunction (INR $>2$ in absence of DIC or \\
\hline & RUQ or epigastric pain & warfarin) \\
\hline & Elevated serum AST, ALT, LDH, or bilirubin & Hepatic haematoma or rupture \\
\hline & Low plasma albumin & \\
\hline \multirow[t]{2}{*}{ Feto-placental } & Abnormal FHR & Abruption with evidence of maternal or fetal compromise \\
\hline & IUGR & Reverse ductus venosus A wave \\
\hline
\end{tabular}

preeclampsia. Most experts suggest a combination of tests, with emphasis on umbilical artery Doppler when there is IUGR.?

Other non-specific risk factors for severe complications of preeclampsia are immigrant status, young maternal age, nulliparity, lower maternal weight, and in the index pregnancy, multiple pregnancy and early-onset preeclampsia. $^{13}$

Definitions of severe preeclampsia vary, but most include multi-organ involvement ${ }^{14-16}$ We modified our definition of severe preeclampsia to preeclampsia associated with one or more severe complications. Severe preeclampsia now warrants delivery regardless of gestational age. Our definition excludes heavy proteinuria and HELLP syndrome, which are not absolute indications for delivery, and includes stroke ${ }^{17}$ and pulmonary edema, which are leading causes of maternal death in preeclampsia. ${ }^{2}$

\section{Other}

A transient hypertensive effect is not associated with an increased risk of adverse outcomes. White-coat effect in early pregnancy $(\sim 30 \%)$ is common. ${ }^{18}$ Forty percent of women progress to persistent hypertension at $\geq 20$ weeks (i.e., gestational hypertension) and $8 \%$ to preeclampsia. Women with white-coat effect have risks (e.g., severe hypertension, preterm delivery, and NICU admission) intermediate between normotension and either preexisting or gestational hypertension. ${ }^{19-24}$

Masked hypertension in early pregnancy $(\sim 30 \%)$ is also common, ${ }^{18}$ but associated perinatal risks are unknown. Outcomes with masked hypertension at $\geq 20$ weeks ( $10 \%)$ equate to those of gestational hypertension. ${ }^{25,26}$ Masked hypertension could be considered (and ambulatory or home BP monitoring performed) if there are unexplained maternal or perinatal complications typically associated with the HDPs. 


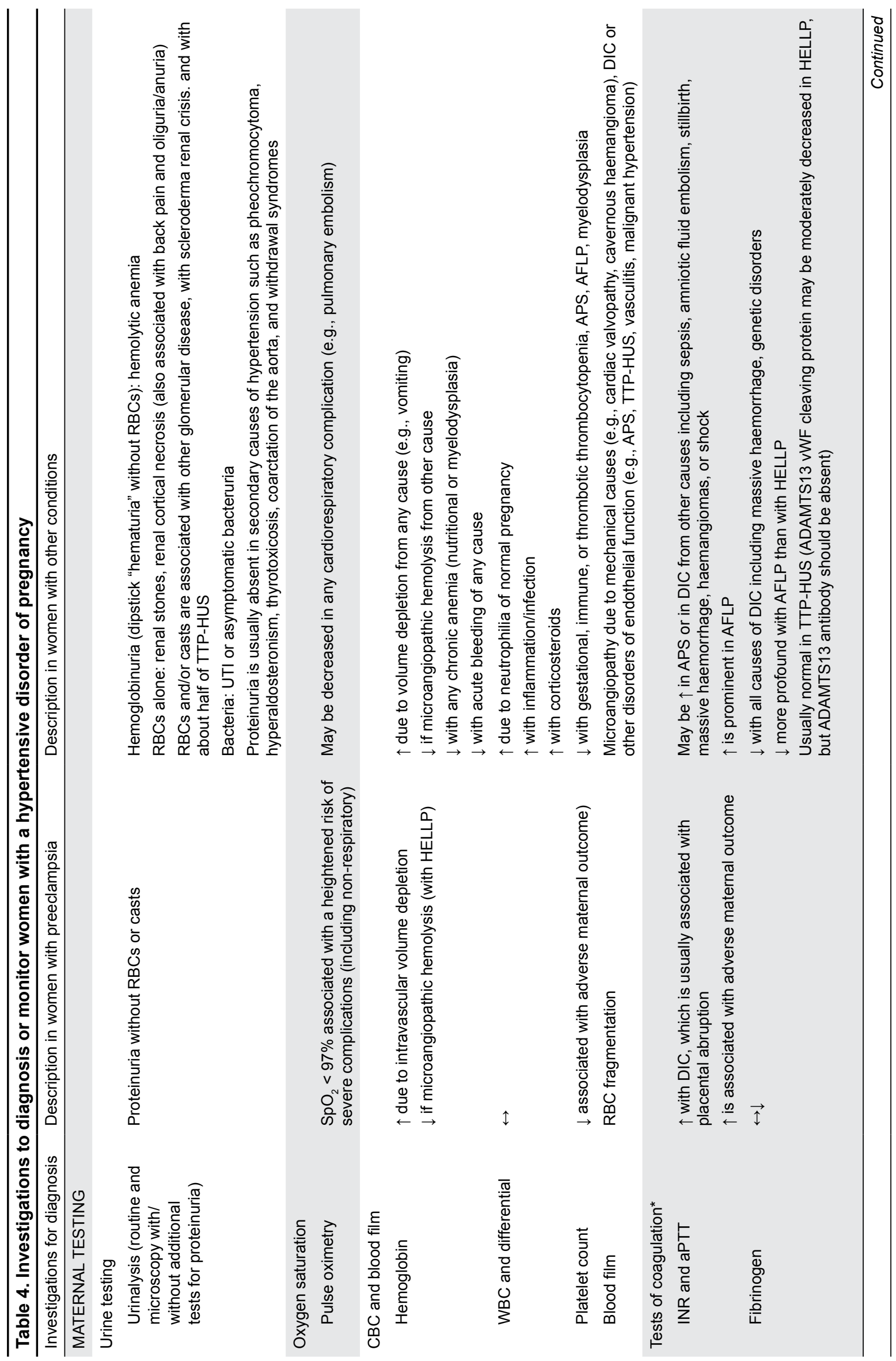




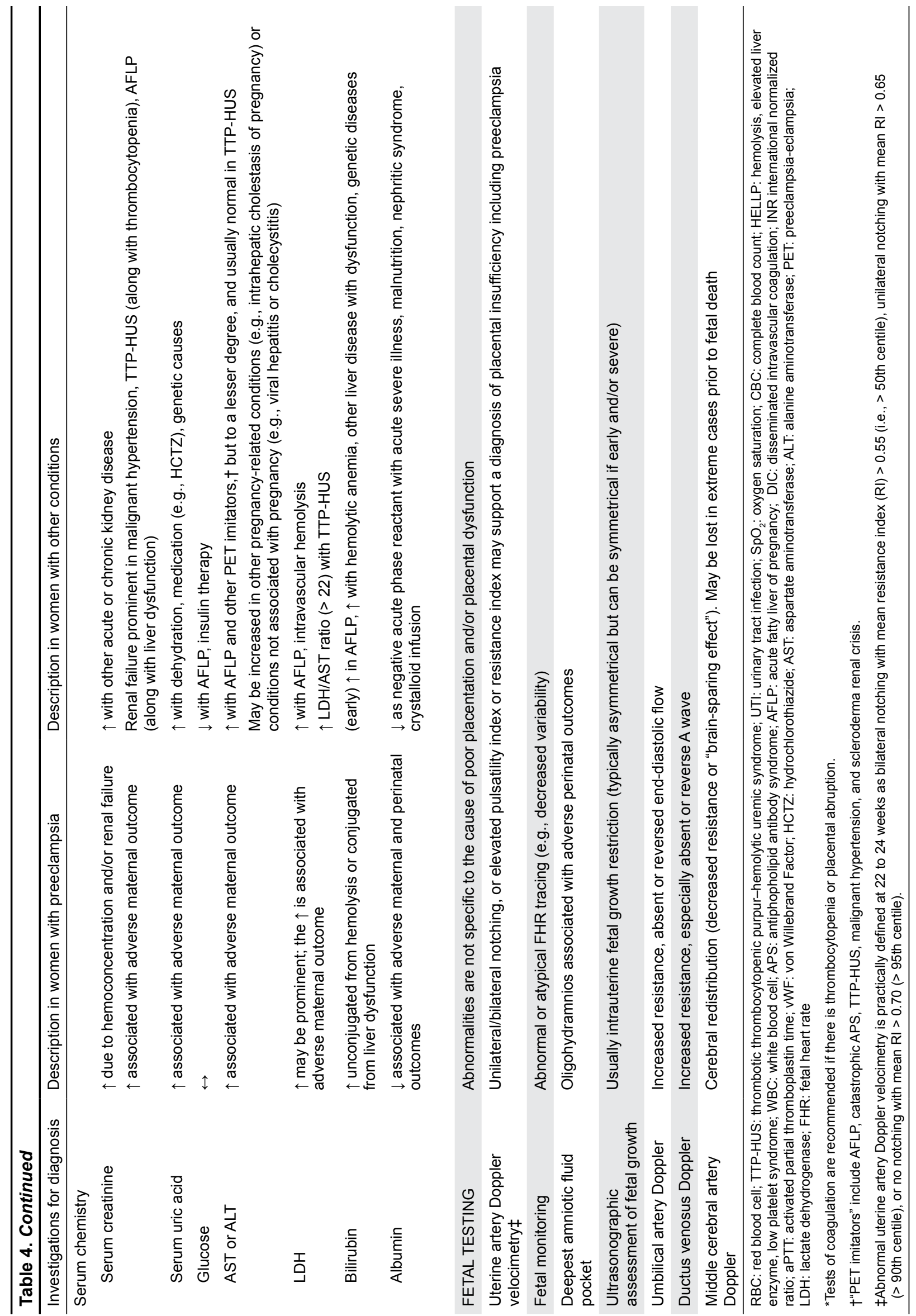




\section{Investigations to Classify HDPs}

\section{Recommendations}

32. For women with pre-existing hypertension, the following should be performed in early pregnancy (if not previously documented): serum creatinine, fasting blood glucose, serum potassium, and urinalysis (III-D), and EKG. (II-2C)

33. Among women with pre-existing hypertension or those with a strong clinical risk marker for preeclampsia, additional baseline laboratory testing may be based on other considerations deemed important by health care providers. (III-C)

34. Women with suspected preeclampsia should undergo the maternal laboratory (II-2B) and pertinent fetal (II-1B) testing. (Table 4)

35. Doppler velocimetry-based assessment of the fetal circulation may be useful to support a placental origin for hypertension, proteinuria, and/or adverse conditions including intrauterine growth restriction, (II-2B) and for the timing of delivery. (I-A)

36. There is insufficient evidence to recommend use of the biophysical profile as part of a schedule of fetal testing in women with a hypertensive disorder of pregnancy. (II-2L)

37. If initial testing is reassuring, but there is ongoing concern about preeclampsia (e.g., change in maternal and/or fetal condition), maternal and fetal testing should be repeated. (III-C)

\section{Comments}

Most abnormalities found in maternal and fetal testing are non-specific. When preeclampsia is suspected, interpretation relies on findings of multiple (not single) abnormalities.

Preeclampsia imitators share manifestations with preeclampsia, but require different treatment. ${ }^{27-31}$ (Table 5)

\section{CHAPTER 2:}

\section{PREDICTION AND PREVENTION}

\section{Predicting Preeclampsia}

\section{Recommendations}

38. Women should be screened for clinical risk markers of preeclampsia from early pregnancy. (II-2C) (Table 6)

39. Consultation with an obstetrician or an obstetric internist, by telephone if necessary, should be considered for women with a history of previous preeclampsia or another strong clinical marker of increased preeclampsia risk, particularly multiple pregnancy, antiphospholipid antibody syndrome, significant proteinuria at first antenatal visit (usually early in pregnancy), or a pre-existing condition of hypertension, diabetes mellitus, or renal disease. (II-2B)

40. Screening using biomarkers or Doppler ultrasound velocimetry of the uteroplacental circulation cannot be recommended routinely at present for women at low or increased risk of preeclampsia until such screening has been shown to improve pregnancy outcome. (II-2C)

\section{Preventing Preeclampsia and its Complications in Women at Low Risk}

We based our recommendations on the need to prevent preeclampsia and/or its associated complications. Pregnant women are classified as being at either low or increased risk of preeclampsia, usually by the presence of one or more of the risk markers in Table 6 (see Predicting Preeclampsia).

Preventative interventions may be best started before 16 weeks' gestation when most of the physiologic transformation of uterine spiral arteries occurs. Such early intervention has the greatest potential to decrease early forms of preeclampsia. ${ }^{32}$

Women at low risk of preeclampsia have usually been from unselected populations of nulliparous and multiparous women.

\section{Recommendations}

41. Calcium supplementation of at least $1 \mathrm{~g} / \mathrm{d}$, orally, is recommended for women with low dietary intake of calcium $(<600 \mathrm{mg} / \mathrm{d})$. (I-A)

42. The following are recommended for other established beneficial effects in pregnancy: abstention from alcohol for prevention of fetal alcohol effects (II-2E), exercise for maintenance of fitness (I-A), periconceptual use of a folate-containing multivitamin for prevention of neural tube defects (I-A), and smoking cessation for prevention of low birthweight and preterm birth. (I-E)

43. Periconceptual and ongoing use of a folatecontaining multivitamin (I-B) or exercise (II-2B) may be useful in preventing preeclampsia.

44. Prostaglandin precursors and supplementation with magnesium or zinc are not recommended for preeclampsia prevention, but may be useful for prevention of other pregnancy complications. (I-C)

45. Dietary salt restriction during pregnancy (I-D), calorie restriction during pregnancy for overweight women (I-D), low-dose acetylsalicylic acid (I-E), vitamins $\mathrm{C}$ and $\mathrm{E}$ (based on current evidence) (I-E), and thiazide diuretics (I-E) are not recommended. 


\begin{tabular}{ll}
\hline Table 5. Preeclampsia imitators \\
\hline Pregnancy related & Not pregnancy related \\
\hline Preeclampsia/HELLP syndrome & Malignant hypertension regardless of the cause \\
Acute fatty liver of pregnancy & Secondary causes of hypertension when associated with end-organ involvement \\
& (e.g., renal disease, pheochromocytoma) \\
& Disseminated intravascular coagulation (from any cause) \\
& Thrombotic thrombocytopenic purpura \\
& Hemolytic uremic syndrome \\
& Vasculitis or other systemic rheumatic condition (systemic lupus erythematous, \\
scleroderma, cryoglobulinemia, catastrophic antiphospholipids syndrome) & Sepsis \\
Medications \\
Cavernous hemangiomas \\
Malignancy \\
\end{tabular}

46. There is insufficient evidence to make a recommendation about a heart-healthy diet (II-2L); workload or stress reduction (including bedrest) (II-2L); supplementation with iron with or without folate (I-L); vitamin D (I-L); pyridoxine (I-L); or food rich in flavonoids. (I-L)

\section{Preventing Preeclampsia and its Complications in Women at Increased Risk}

Women at increased risk of preeclampsia are most commonly identified by a personal or family history of an HDP, chronic medical disease, and/or abnormal uterine artery Doppler before 24 weeks' gestation. Combining clinical, biochemical, and/or ultrasonographic risk markers may better identify women at increased preeclampsia risk (see "Prediction"); however, no intervention trial has used such an approach to evaluate preventative therapy. ${ }^{33,34}$

\section{Recommendations}

47. Low-dose acetylsalicylic acid and calcium supplementation (of at least $1 \mathrm{~g} / \mathrm{d}$ ) for women with low calcium intake are recommended for preventions of preeclampsia in women at high risk. (I-A)

48. Acetylsalicylic acid should be: taken in a low dose (75-162 mg/d), (III-B) administered at bedtime, (I-B) initiated after diagnosis of pregnancy but before 16 weeks' gestation, (I-B) and considered for continuation until delivery. (I-C)

49. Prophylactic doses of low-molecular-weight heparin may be discussed in women with previous placental complications (including preeclampsia) to prevent the recurrence of severe or early-onset preeclampsia, preterm delivery, and/or infants that are small for gestational age. (I-B)
50. The following may be useful: L-arginine (I-B), increased rest at home in the third trimester (I-C), and reduction of workload or stress. (III-C)

51. The following may be useful for prevention of other pregnancy complications: prostaglandin precursors (I-B), magnesium supplementation (I-C), and heparin to prevent venous thromboembolic disease. (I-B)

52. The following are recommended for other established beneficial effects in pregnancy (as discussed for women at low risk of preeclampsia): abstention from alcohol (II-2E), periconceptual use of a folate-containing multivitamin (I-A), and smoking cessation. (I-E)

53. The following are not recommended: calorie restriction in overweight women during pregnancy (I-D), weight maintenance in obese women during pregnancy (III-D), antihypertensive therapy specifically to prevent preeclampsia (I-D), and vitamins $C$ and $E$. (I-E)

54. There is insufficient evidence to make a recommendation about the usefulness of the following: the heart-healthy diet (III-L); exercise (I-L); selenium (I-L); garlic (I-L); zinc, pyridoxine, iron (with or without folate), vitamin $\mathrm{D}$, or multivitamins with/without micronutrients. (III-L)

\section{CHAPTER 3:}

\section{TREATMENT OF THE HDPS}

\section{Dietary and Lifestyle Changes}

\section{Recommendations}

55. There is insufficient evidence to make a recommendation about the usefulness of the following: new severe dietary salt restriction for 


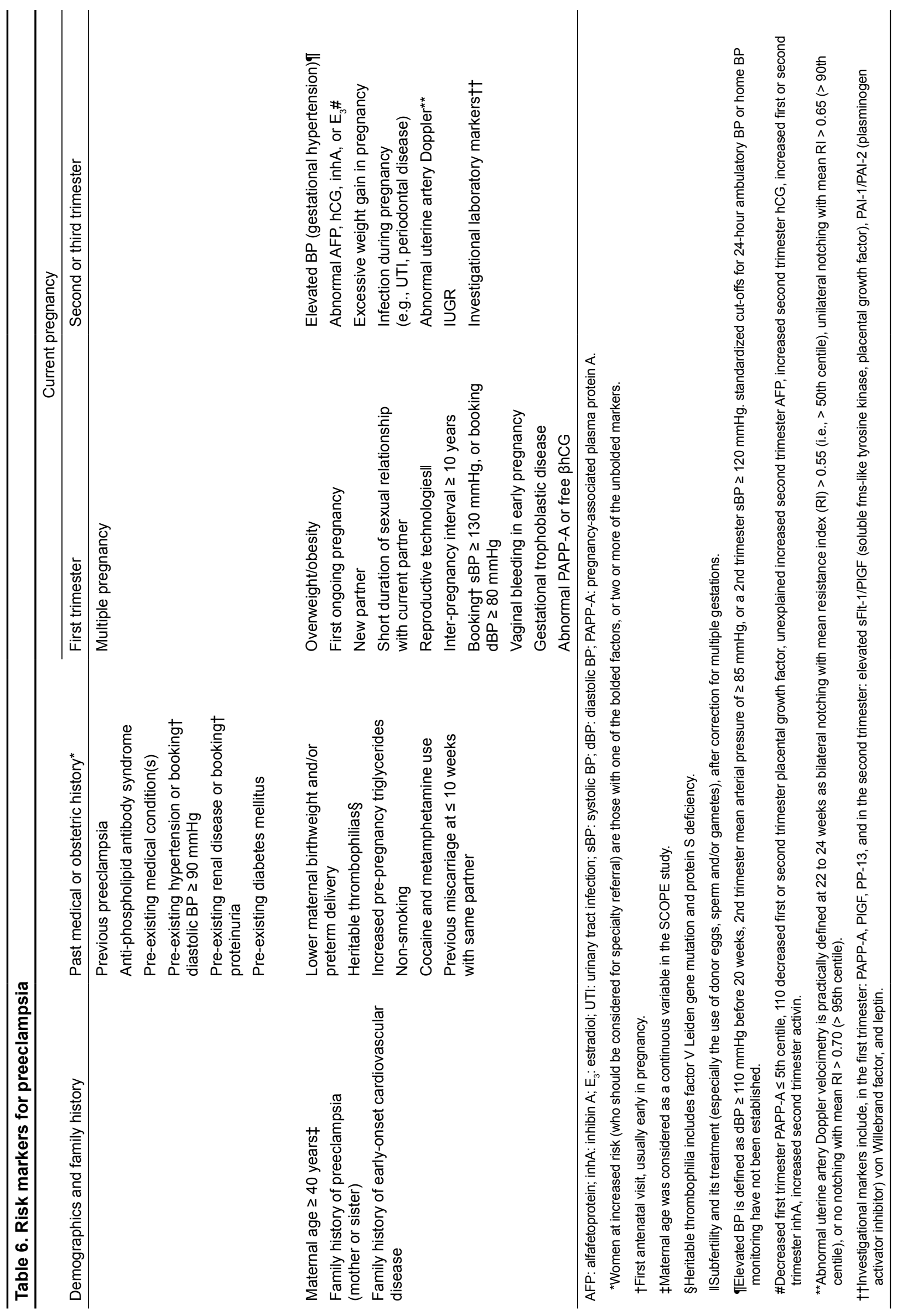




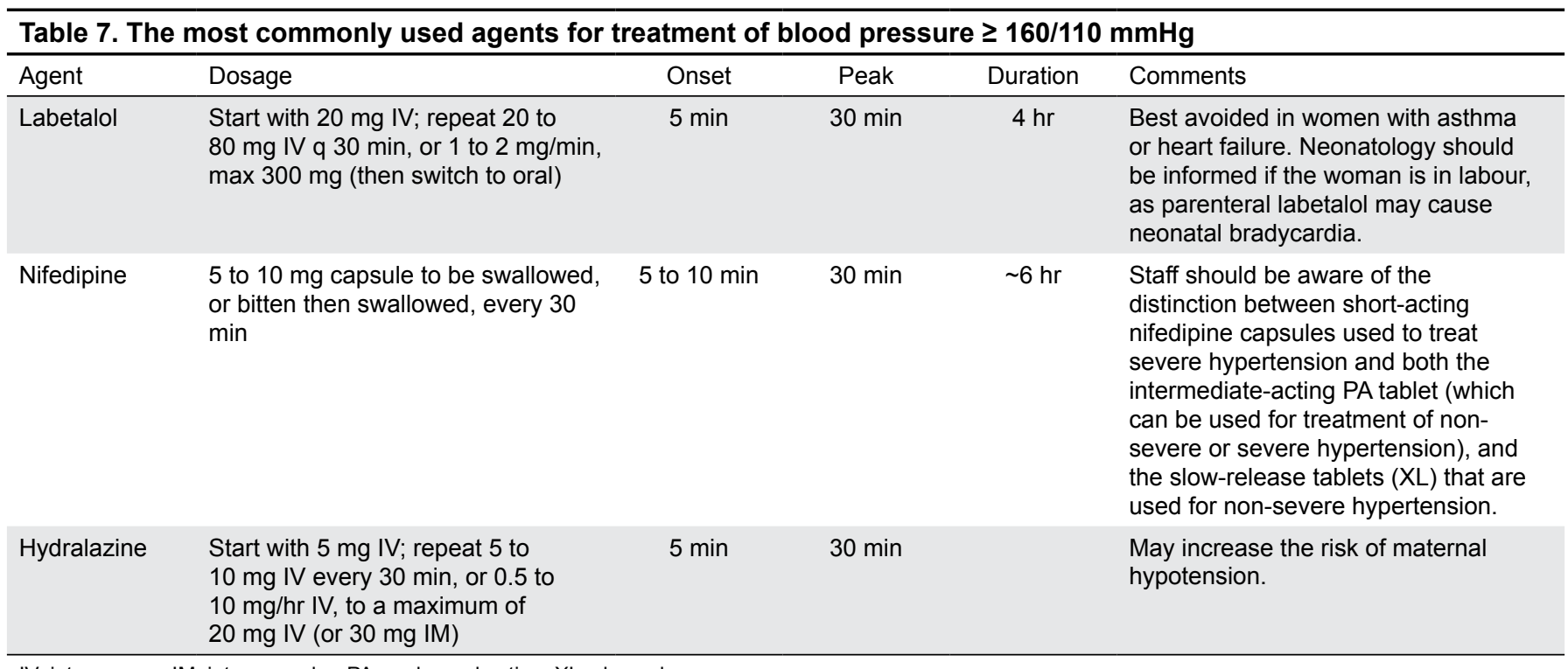

IV: intravenous; IM: intramuscular; PA: prolonged action; XL: slow release

women with any HDP, ongoing salt restriction among women with pre-existing hypertension, heart-healthy diet, and calorie restriction for obese women. (III-L)

56. There is insufficient evidence to make a recommendation about the usefulness of exercise, workload reduction, or stress reduction. (III-L)

57. For women with gestational hypertension (without preeclampsia), some bed rest in hospital (vs. unrestricted activity at home) may be useful to decrease severe hypertension and preterm birth. (I-B)

58. For women with preeclampsia who are hospitalized, strict bed rest is not recommended. (I-D)

59. For all other women with an HDP, the evidence is insufficient to make a recommendation about the usefulness of some bed rest, which may nevertheless be advised based on practical considerations. (III-C)

The following recommendations apply to women with either pre-existing or gestational hypertension.

\section{Place of Care}

\section{Recommendations}

60. In-patient care should be provided for women with severe hypertension or severe preeclampsia. (II-2B).

61. A component of care through hospital day units or home care can be considered for women with nonsevere preeclampsia or non-severe pre-existing or gestational hypertension. (I-B, II-2B)

\section{Antihypertensive Therapy for Severe Hypertension}

\section{Recommendations}

62. Blood pressure should be lowered to $<160 \mathrm{mmHg}$ systolic and $<110 \mathrm{mmHg}$ diastolic. (I-A)

63. Initial antihypertensive therapy in the hospital setting should be with nifedipine short-acting capsules, parenteral hydralazine, or parenteral labetalol. (I-A) (Table 7)

64. Alternative antihypertensive medications include a nitroglycerin infusion (I-B), oral methyldopa (I-B), oral labetalol (I-B), oral clonidine (III-B), or postpartum, oral captopril. (III-B)

65. Refractory hypertension may be treated with sodium nitroprusside. (III-B)

66. Nifedipine and magnesium sulphate can be used contemporaneously. (II-2B)

67. Magnesium sulphate is not recommended solely as an antihypertensive agent. (I-E)

68. Continuous fetal heart rate monitoring is advised until blood pressure is stable. (III-L)

\section{Antihypertensive Therapy for Non-Severe Hypertension Without Comorbid Conditions}

\section{Recommendations}

69. Antihypertensive drug therapy may be used to keep systolic blood pressure at 130 to $155 \mathrm{mmHg}$ and diastolic blood pressure at 80-105 mmHg. (I-B) 
Table 8. Doses of the most commonly used agents for treatment of blood pressures 149 to $159 / 90$ to $105 \mathrm{mmHg}$

\begin{tabular}{lll}
\hline Agent & Dosage & Comments \\
\hline Methyldopa & 250 to $500 \mathrm{mg}$ po bid-qid $(\max 2 \mathrm{~g} / \mathrm{d})$ & There is no evidence to support a loading dose of methyldopa. \\
Labetalol & 100 to $400 \mathrm{mg}$ po bid-tid $(\max 1200 \mathrm{mg} / \mathrm{d})$ & $\begin{array}{l}\text { Some experts recommend a starting dose of } 200 \mathrm{mg} \text { po bid. } \\
\text { Nifedipine* }\end{array}$ \\
& XL preparation $(20$ to $60 \mathrm{mg}$ po OD, $\max 120 \mathrm{mg} / \mathrm{d})$ & $\begin{array}{l}\text { Ensure that the correct form of nifedipine has been prescribed } \\
\text { so that the XL preparation is not confused with the capsules. }\end{array}$ \\
\hline
\end{tabular}

$\mathrm{XL}$ : slow release

*The prolonged action nifedipine tablet is no longer available in Canada

70. The choice of antihypertensive agent for initial treatment should be based on characteristics of the patient, contraindications to a particular drug, and physician and patient preference. (III-C)

71. Initial therapy in pregnancy can be with one of a variety of antihypertensive agents available in Canada: methyldopa (I-A), labetalol (I-A), other beta-blockers (acebutolol, metoprolol, pindolol, and propranolol), (I-B) and calcium channel blockers (nifedipine). (I-A) (Table 8)

72. Angiotensin-converting enzyme inhibitors and angiotensin receptor blockers should not be used during pregnancy. (II-2E)

73. Atenolol and prazosin are not recommended prior to delivery. (I-D)

\section{For Non-Severe Hypertension (BP of 140-159/ 90-109 mmHg) With Comorbid Conditions}

\section{Recommendations}

74. For women with comorbid conditions, antihypertensive drug therapy should be used to keep systolic blood pressure at $<140 \mathrm{mmHg}$ and diastolic blood pressure at $<90 \mathrm{mmHg}$. (III-C)

75. Initial therapy in pregnancy can be with one of a variety of antihypertensive agents as listed for women without co-morbidities. (III-C)

76. Captopril, enalapril, or quinapril may be used postpartum, even during breastfeeding. (III-B)

\section{Corticosteroids for Acceleration of Fetal Pulmonary Maturity}

\section{Recommendations}

77. Antenatal corticosteroid therapy should be considered for all women who present with preeclampsia at $\leq 34+6$ weeks' gestation. (I-A)

78. Antenatal corticosteroid therapy should be considered for women who present at $\leq 34+6$ weeks' gestation with gestational hypertension (despite the absence of proteinuria or adverse conditions) only if delivery is contemplated within the next 7 days. (III-L)

79. A rescue dose of corticosteroids may be considered for women at $\leq 34+6$ weeks' gestation who remain at high risk of preterm delivery 7 days or more after an initial course of antenatal corticosteroids. (I-C)

80. Antenatal corticosteroids may be considered for women delivered by elective Caesarean delivery at $\leq 38+6$ weeks' gestation to reduce respiratory morbidity. (I-B)

\section{Comments}

When administered at $\leq 34+6$ weeks' gestation, antenatal corticosteroids accelerate fetal pulmonary maturity and decrease neonatal mortality and morbidity, including among women with HDPs. ${ }^{35}$ RCTs that administered steroids at $33+0$ to $34+6$ weeks resulted in reduced neonatal RDS..$^{35}$

Prior to elective Caesarean section at $\leq 38+6$ weeks' gestation, antenatal corticosteroids decrease the excess neonatal respiratory morbidity and NICU admissions. ${ }^{36,37}$ All subgroup analyses have not necessarily revealed such benefits following Caesarean or vaginal delivery. ${ }^{35}$

\section{Timing of Delivery for Women With Preeclampsia}

Delivery is the only intervention that initiates resolution of preeclampsia, and women with gestational hypertension or pre-existing hypertension may develop preeclampsia.

\section{Recommendations}

81. Consultation with an obstetrician (by telephone if necessary) is mandatory in women with severe preeclampsia. (III-B)

82. All women with severe preeclampsia should be delivered immediately (either vaginally or by Caesarean), regardless of gestational age. (III-C)

83. For women with non-severe preeclampsia at $<24+0$ weeks' gestation, counselling should include, as an option, information about delivery within days. (II-2B)

84. For women with non-severe preeclampsia at $24+0$ to $33+6$ weeks' gestation, expectant management 
should be considered, but only in perinatal centres capable of caring for very preterm infants. (I-B)

85. For women with non-severe preeclampsia at $34+0$ to $36+6$ weeks' gestation, there is insufficient evidence to make a recommendation about the benefits or risks of expectant management. (III-L)

86. For women with preeclampsia at $\geq 37+0$ weeks' gestation, immediate delivery is recommended. (I-A)

87. For women with non-severe preeclampsia complicated by hemolysis, elevated liver enzymes, low platelets syndrome at $24+0$ to $34+6$ weeks' gestation, consider delaying delivery long enough to administer antenatal corticosteroids for acceleration of fetal pulmonary maturity if there is temporary improvement in maternal laboratory testing. (II-2B)

88. All women with hemolysis, elevated liver enzymes, low platelets syndrome at $\geq 35+0$ weeks' gestation should be considered for immediate delivery. (II-2B)

\section{Timing of Delivery for Women With Gestational Hypertension}

\section{Recommendations}

89. For women with gestational hypertension (without preeclampsia) at $\geq 37+0$ weeks' gestation, delivery within days should be discussed. (I-B)

90. For women with gestational hypertension (without preeclampsia) at $<37+0$ weeks' gestation, there is insufficient evidence to make a recommendation about the benefits or risks of expectant management. (III-L)

\section{Timing of Delivery for Women With Pre-Existing Hypertension}

\section{Recommendation}

91. For women with uncomplicated pre-existing hypertension who are otherwise well at $\geq 37+0$ weeks' gestation, delivery should be considered at $38+0$ to $39+6$ weeks' gestation. (II-1B)

\section{Mode of Delivery}

\section{Recommendations}

92. For women with any hypertensive disorder of pregnancy, vaginal delivery should be considered unless a Caesarean delivery is required for the usual obstetric indications. (II-2B)
93. If vaginal delivery is planned and the cervix is unfavourable, then cervical ripening should be used to increase the chance of a successful vaginal delivery. (1-A)

94. At a gestational age remote from term, women with a hypertensive disorder of pregnancy with evidence of fetal compromise may benefit from delivery by emergency Caesarean section. (II-2B)

95. Antihypertensive treatment should be continued throughout labour and delivery to maintain systolic blood pressure at $<160 \mathrm{mmHg}$ and diastolic blood pressure at $<110 \mathrm{mmHg}$. (II-2B)

96. The third stage of labour should be actively managed with oxytocin, 5 units intravenous or 10 units intramuscular, particularly in the presence of thrombocytopenia or coagulopathy. (I-A)

97. Ergometrine maleate should not be administered to women with any hypertensive disorder of pregnancy, particularly preeclampsia or gestational hypertension; alternative oxytocics should be considered. (II-3D)

\section{Anaesthesia: General Principles}

\section{Recommendations}

98. The anaesthesiologist should be informed when a woman with preeclampsia is admitted to the delivery suite. (II-3B)

99. Early insertion of an epidural catheter (in the absence of contraindications) is recommended for control of labour pain. (I-A)

100. In the absence of contraindications, all of the following are acceptable methods of anaesthesia for women undergoing Caesarean delivery: epidural, spinal, combined spinal-epidural, and general anaesthesia. (I-A)

101. A routine fixed intravenous fluid bolus should not be administered prior to neuraxialanaesthesia. (I-E)

\section{Anaesthesia: Fluid Administration}

\section{Recommendations}

102. Intravenous and oral fluid intake should be minimized in women with preeclampsia, to avoid pulmonary edema. (II-2B)

103. Fluid should not be routinely administered to treat oliguria $(<15 \mathrm{~mL} / \mathrm{hr}$ for 6 consecutive hours). (III-D)

104. For treatment of persistent oliguria, neither dopamine nor furosemide is recommended. (I-E) 
105. Phenylephrine or ephedrine may be used to prevent or treat hypotension during neuraxial anaesthesia. (I-A)

\section{Monitoring}

\section{Recommendations}

106. Arterial line insertion may be used for continuous arterial blood pressure monitoring when blood pressure control is difficult or there is severe bleeding. (II-3B)

107. Central venous pressure monitoring is not routinely recommended, and if a central venous catheter is inserted, it should be used to monitor trends and not absolute values. (II-2D)

108. Pulmonary artery catheterization is not recommended unless there is a specific associated indication (III-D), and then only in an intensive care unit setting. (III-B)

\section{Coagulation}

\section{Recommendations}

109. Upon admission to delivery suite, women with preeclampsia should have a platelet count done. (II-1A)

110. Neuraxial analgesia and/or anaesthesia are appropriate in women:

a. with preeclampsia, provided there are no associated coagulation concerns (II-2E) (Table 9);

b. with a platelet count $\geq 75 \times 10^{9} / \mathrm{L}$, (II-2B);

c. taking low-dose acetylsaliclylic acid in the presence of an adequate platelet count (I-A);

d. receiving unfractionated heparin in a dose of $\leq 10000 \mathrm{IU} / \mathrm{d}$ subcutaneously, 4 hours after the last dose and possibly immediately after the last dose without any delay (III-B);

e. receiving unfractionated heparin in a dose $>10000 \mathrm{IU} / \mathrm{d}$ subcutaneously if they have a normal activated partial thromboplastin time 4hours after the last dose (III-B);

f. receiving intravenous heparin in a therapeutic dose if they have a normal activated partial thromboplastin time 4 hours after the last dose (III-B); or

g. receiving low-molecular-weight heparin 10 to 12 hours after a prophylactic dose, or 24 hours after a therapeutic dose. (III-B)

\section{Aspects of Care Specific to Women With Pre-Existing Hypertension}

\section{Recommendations}

111. Pre-conceptual counselling for women with pre-existing hypertension is recommended. (III-C)

112. The following antihypertensive drugs are all acceptable for use in the first trimester of pregnancy: methyldopa, labetalol, and nifedipine. (II-2B)

113. Angiotensin-converting enzyme inhibitors and angiotensin receptor blockers should be discontinued when planning pregnancy or as soon as pregnancy is diagnosed. (II-2D)

114. Atenolol should be discontinued when pregnancy is diagnosed. (I-D)

115. Planned changes in antihypertensive agent(s) for care in pregnancy should be made while the woman is planning pregnancy if the woman has uncomplicated pre-existing hypertension, or, if in the presence of comorbid conditions, she is likely to conceive easily (within 12 months). (III-L)

\section{Aspects of Care for Women With Preeclampsia: Magnesium Sulphate for Preventing or Treating Eclampsia}

\section{Recommendations}

116. Magnesium sulphate is recommended for first-line treatment of eclampsia. (I-A)

117. Magnesium sulphate is recommended as prophylaxis against eclampsia in women with severe preeclampsia. (I-A)

118. Magnesium sulphate may be considered as prophylaxis against eclampsia in women with non-severe preeclampsia but with severe hypertension, headaches/visual symptoms, right upper quadrant/epigastric pain, platelet count $<100000 \times 10^{9} / \mathrm{L}$, progressive renal insufficiency, and/or elevated liver enzymes, based on cost considerations. (I-C)

119. Magnesium sulphate should be used in standard dosing, usually $4 \mathrm{~g}$ intravenous loading dose followed by $1 \mathrm{~g}$ /hour. (I-A)

120. Routine monitoring of serum magnesium levels is not recommended. (I-E)

121. Phenytoin and benzodiazepines should not be used for eclampsia prophylaxis or treatment, unless there is a contraindication to magnesium sulphate or it is ineffective. (I-E) 
Table 9. Eligibility for neuraxial anaesthesia

\begin{tabular}{|c|c|c|c|}
\hline $\begin{array}{l}\text { Treatment with ASA } \\
\text { or heparin }\end{array}$ & Normal platelet count & $\begin{array}{l}\text { Low platelet count } \\
\text { (normal INR and aPTT) }\end{array}$ & $\begin{array}{l}\text { Abnormal INR or } \\
\text { aPTT (regardless of } \\
\text { platelet count) }\end{array}$ \\
\hline None or low-dose ASA & $\checkmark$ & $\begin{array}{l}\checkmark \text { if platelet count }>75 \times 10^{9} / \mathrm{L} \\
\text { Unclear if platelet count } 50 \text { to } 75 \times 10^{9} / \mathrm{L} \\
X \text { if platelet count }<50 \times 10^{9} / \mathrm{L}\end{array}$ & \multirow{8}{*}{ 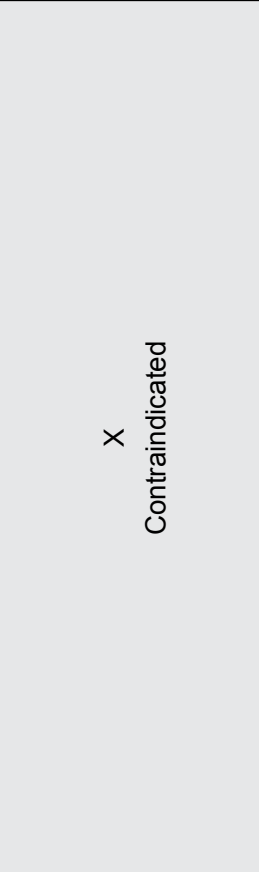 } \\
\hline \multicolumn{4}{|l|}{ UFH } \\
\hline$\leq 10000 \mathrm{IU} / \mathrm{d}(\mathrm{SC}) \dagger$ & $\begin{array}{l}\checkmark \\
0 \text { to } 4 \mathrm{hr} \text { after last dose }\end{array}$ & Unclear & \\
\hline$>10000 \mathrm{IU} / \mathrm{d}(\mathrm{SC}) \ddagger$ & $\checkmark$ & Unclear & \\
\hline Therapeutic dose (IV) & $\begin{array}{l}4 \mathrm{hr} \text { after last dose and a } \\
\text { normal aPTT } \\
\checkmark \\
4 \mathrm{hr} \text { after last dose and a } \\
\text { normal aPTT }\end{array}$ & Unclear & \\
\hline \multicolumn{3}{|l|}{ LMWH } & \\
\hline Prophylactic dose & $\begin{array}{l}\checkmark \\
10 \text { to } 12 \mathrm{hr} \text { after last dose }\end{array}$ & Unclear & \\
\hline Therapeutic dose & $\begin{array}{l}\checkmark \\
24 \mathrm{hr} \text { after last dose }\end{array}$ & Unclear & \\
\hline $\begin{array}{l}\text { Low dose ASA + prophylactic UFH } \\
\text { or LMWH§ }\end{array}$ & Unclear $\|$ & Unclear & \\
\hline \multicolumn{4}{|c|}{$\begin{array}{l}\text { INR: international normalized ratio; aPTT: activated partial thromboplastin time; UFH: unfractionated heparin; SC: subcutaneous; IV: intravenous; } \\
\text { LMWH: low-molecular-weight heparin }\end{array}$} \\
\hline $\begin{array}{l}\text { Note: These recommendations are base } \\
{ }^{*} \text { Other than a lupus anticoagulant } \\
\text { †Prophylactic dosing is defined as } \leq 10 \\
\ddagger \text { Therapeutic dosing (SC) is defined as } \\
\text { §Prophylactic doses of UFH are defined } \\
\text { \|Unless ASA is stopped } 7 \text { days or more }\end{array}$ & $\begin{array}{l}\text { osence of a rapidly falling platele } \\
\mathrm{J} / \mathrm{d} \\
0 \mathrm{IU} / \mathrm{d} \\
\text { ivery }\end{array}$ & unt or a known platelet dysfunction (e.g., von W & rand's disease). \\
\hline
\end{tabular}

122. In women with pre-existing or gestational hypertension, magnesium sulphate should be considered for fetal neuroprotection in the setting of imminent preterm birth (within the next 24 hours) at $\leq 31+6$ weeks. (1-A)

123. Delivery should not be delayed in order to administer antenatal magnesium sulphate for fetal neuroprotection if there are maternal and/or fetal indications of emergency delivery. (III-E)

There is no international consensus on what defines severe preeclampsia. This document defines it as preeclampsia requiring delivery due to serious maternal end-organ involvement and/or fetal compromise (see "Classification of HDPs"). For eclampsia prevention in the setting of non-severe preeclampsia, we have added to the indication for magnesium sulphate (in Recommendation 120) the following symptoms/signs as these are included in the definition of severe preeclampsia by other organizations: severe hypertension, headaches/visual symptoms, right upperquadrant/epigastric pain, platelet count $<100000 \times$ $10^{\circ} / \mathrm{L}$, progressive renal insufficiency, and/or elevated liver enzymes.

\section{Aspects of Care for Women With Preeclampsia: Plasma Volume Expansion}

\section{Recommendation}

124. Plasma volume expansion is not recommended for women with preeclampsia. (I-E)

\section{Therapies for HELLP Syndrome}

\section{Recommendations}

125. Every obstetrical centre should be aware of the local delay between ordering and receiving platelets units. (III-B)

126. For a platelet count of $<20 \times 10^{9} / \mathrm{L}$ with hemolysis, elevated liver enzymes, low platelets 


\begin{tabular}{|c|c|c|}
\hline \multirow[b]{2}{*}{ Platelet count } & \multicolumn{2}{|c|}{ Mode of delivery } \\
\hline & Caesarean delivery & Vaginal delivery \\
\hline$<20 \times 10 \% / L$ & $\checkmark$ & $\checkmark$ \\
\hline 20 to $49 \times 10^{9} / \mathrm{L}$ & $\checkmark$ & $\begin{array}{l}\text { Consider in presence of: } \\
\text { - excessive active bleeding } \\
\text { - known platelet dysfunction } \\
\text { - platelet count falling rapidly } \\
\text { - coagulopathy }\end{array}$ \\
\hline$\geq 50 \times 10^{9} / \mathrm{L}$ & $\begin{array}{l}\text { Consider in presence of: } \\
\text { - excessive active bleeding } \\
\text { - known platelet dysfunction } \\
\text { - platelet count falling rapidly } \\
\text { - coagulopathy }\end{array}$ & $\begin{array}{l}\text { Consider in presence of: } \\
\text { - excessive active bleeding } \\
\text { - known platelet dysfunction } \\
\text { - platelet count falling rapidly } \\
\text { - coagulopathy }\end{array}$ \\
\hline Regardless of the platelet count & \multicolumn{2}{|c|}{$\begin{array}{l}\text { No platelets should be transfused if there is a strong suspicion of HIT } \\
\text { or TTP-HUS }\end{array}$} \\
\hline HIT: heparin-induced thrombocytopen & TTP-HUS: thrombotic thrombocyto & pura-hemolytic uremic syndrome \\
\hline
\end{tabular}

syndrome, platelet transfusion is recommended regardless of mode of delivery. (III-B) (Table 9)

127. For a platelet count of $20 \times 10^{9}$ to $49 \times 10^{9} / \mathrm{L}$ with hemolysis, elevated liver enzymes, low platelets syndrome, platelet transfusion is recommended prior to Caesarean delivery. (III-B) (Table 9)

128. For a platelet count of $20 \times 10^{9}$ to $49 \times 10^{9} / \mathrm{L}$ with hemolysis, elevated liver enzymes, low platelets syndrome, platelet transfusion should be considered prior to vaginal delivery if there is excessive active bleeding, known platelet dysfunction, a rapidly falling platelet count, or coagulopathy. (II-2D) (Table 10)

129. For a platelet count of $\geq 50 \times 10^{9} / \mathrm{L}$ with hemolysis, elevated liver enzymes, low platelets syndrome, platelet transfusion and/or packed red blood cells should be considered prior to either Caesarean or vaginal delivery only if there is excessive active bleeding, known platelet dysfunction, a rapidly falling platelet count, or coagulopathy. (III-B)

130. We do not recommend corticosteroids for treatment of hemolysis, elevated liver enzymes, low platelets syndrome until they have been proven to decrease maternal morbidity. (II-3L)

131. We recommend against plasma exchange or plasmapheresis for hemolysis, elevated liver enzymes, low platelets syndrome, particularly within the first 4 days postpartum. (II-3E)

\section{Care in the 6 Weeks Postpartum}

\section{Recommendations}

132. Blood pressure should be measured during the time of peak postpartum blood pressure, at days 3 to 6 after delivery. (III-B)

133. Women with postpartum hypertension should be evaluated for preeclampsia (either arising de novo or worsening from the antenatal period). (II-2B)

134. Consideration should be given to continuing antihypertensive therapy postpartum, particularly in women with antenatal preeclampsia and those who delivered preterm. (II-2L)

135. Severe postpartum hypertension must be treated with antihypertensive therapy to keep systolic blood pressure $<160 \mathrm{mmHg}$ and diastolic blood pressure $<110 \mathrm{mmHg}$. (I-A)

136. In women without co-morbidities, antihypertensive therapy should be considered to treat non-severe postpartum hypertension to keep blood pressure $<140 / 90 \mathrm{mmHg}$. (III-L)

137. Women with co-morbidities other than pre-gestational diabetes mellitus should be treated to keep blood pressure $<140 / 90 \mathrm{mmHg}$ (III-C)

138. Women with pre-gestational diabetes mellitus should be treated to keep blood pressure $<$ 130/80 mmHg. (III-C)

139. Antihypertensive agents generally acceptable for use in breastfeeding include the following: nifedipine XL, labetalol, methyldopa, captopril, and enalapril. (III-B) 
140. There should be confirmation that end-organ dysfunction of preeclampsia has resolved. (III-C)

141. Non-steroidal anti-inflammatory drugs should not be given postpartum if hypertension is difficult to control, there is evidence of kidney injury (oliguria and/or creatinine $\geq 90 \mu \mathrm{M}$ ), or platelets are $<50$ to $10^{9} / \mathrm{L}$. (III-C)

142. Postpartum thromboprophylaxis should be considered in women with preeclampsia, particularly in the presence of other risk factors. (II-2B)

\section{Care Beyond 6 Weeks Postpartum}

\section{Recommendations}

143. Women with a history of severe preeclampsia (particularly those who presented or delivered before 34 weeks' gestation) should be screened for pre-existing hypertension and underlying renal disease. (II-2B)

144. Referral for internal medicine or nephrology consultation (by telephone if necessary) should be considered for women with:

(i) postpartum hypertension that is difficult to control, or

(ii) women who had preeclampsia and have at 3-6 months postpartum either ongoing proteinuria, decreased estimated glomerular filtration rate (eGFR) $(<60 \mathrm{~mL} / \mathrm{min})$, or another indication of renal disease, such as abnormal urinary sediment. (III-A)

145. Women who are overweight should be encouraged to attain a healthy body mass index to decrease risk in future pregnancy (II-2A) and for long-term health. (I-A)

146. Women with pre-existing hypertension or persistent postpartum hypertension should undergo the following investigations (if not done previously) at least six weeks postpartum: urinalysis; serum sodium, potassium and creatinine; fasting glucose; fasting lipid profile; and standard 12-lead electrocardiography. (III-L)

147. Women who are normotensive but who have had a hypertensive disorder of pregnancy, may benefit from assessment of traditional cardiovascular risk markers. (II-2B)

148. All women who have had a hypertensive disorder of pregnancy should pursue a healthy diet and lifestyle. (I-B)

\section{Effects of Maternal Hypertension and Its Therapies on Child Neurobehavioural Development}

\section{Recommendations}

149. Clinicians should be aware that gestational hypertension and preeclampsia may each be associated with an increase in adverse paediatric neurodevelopmental effects, such as inattention and externalizing behaviours (e.g., aggressiveness). (II-2B).

150. Clinicians should be reassured that there is no compelling evidence that antihypertensive medications (specifically labetalol, nifedipine, or methyldopa) are themselves associated with clear adverse neurodevelopmental effects. (I-B)

\section{CHAPTER 4: \\ PATIENT PERSPECTIVE}

\section{Recommendations}

151. Health care providers should be alert to symptoms of posttraumatic stress following a hypertensive disorder of pregnancy and refer women for appropriate evaluation and treatment. (II-2B)

152. Health care providers should inform their patients, antepartum and postpartum, about preeclampsia, its signs and symptoms, and the importance of timely reporting of symptoms to health care providers. (II-2B)

153. Information should be re-emphasized at subsequent visits. (III-C)

\section{CHAPTER 5: KNOWLEDGE TRANSLATION TOOLS AND IMPLEMENTATION OF THE GUIDELINE}

The Appendix (Table 10 in the full document ${ }^{3}$ ) lists tools to support the application of this guideline. Some websites provide general information about BP measurement for non-pregnant patients, but the recommendations are similar enough to those for pregnant women to be useful. Patients, their partners, and their care providers should be well educated about the HDP, and relevant sites are listed.

Implementation of any evidence depends on individual knowledge and beliefs, as well as institutional culture. Strong recommendations should be incorporated into clinical practice. In well-resourced settings, almost all preeclampsiarelated maternal deaths involve substandard care. ${ }^{38}$

Some updates to the 2008 SOGC guidelines on the HDP may require additional effort to implement. 
Recommendation 9 states that all measurement devices used in hospitals or offices should be checked regularly against a calibrated device may not be possible for all Canadian hospitals and offices to do on a regular basis.

Physicians should consider the category "other HDP" (white-coat and masked hypertension) as part of the classification of hypertensive women and consider using some form of out-of-office BP measurement to evaluate women with non-severe pre-existing or gestational hypertension.

Health care providers should inform pregnant women about the symptoms and signs of the HDPs and refer them to appropriate knowledge translation tools.

We recommend the use of corticosteroids for women $\leq 34+6$ weeks' gestation who are at high risk of delivery within the next seven days. This gestational age cut-off represents a fundamental change in practice that will require discussion.

Physicians should be familiar with the blood bank policies of their own hospital.

Physicians should be aware of postpartum signs of maternal posttraumatic stress disorder and the maternal and perinatal long-term effects of HDPs, especially at this vulnerable time in maternal care when the maternity care provider is often handing back care to the primary care physician.

The reader is reminded to refer to the full open-access guideline published in Pregnancy Hypertension, ${ }^{3}$ which contains not only the recommendations and tables presented here, but also all explanatory text and additional references.

\section{REFERENCES}

1. Health Canada. Special report on maternal mortality and severe morbidity in Canada. Enhanced surveillance: the path to prevention. Ottawa: Minister of Public Works and Government Services Canada; 2004.

2. Centre for Maternal and Child Enquiries. Saving mothers' lives: reviewing maternal deaths to make motherhood safer: 2006-08. The eighth report on confidential enquiries into maternal deaths in the United Kingdom. BJOG 2011;118(Suppl 1):1-203.

3. Magee LA, Pels A, Helewa M, Rey E, Von Dadelszen P; Canadian Hypertensive Disorders of Pregnancy (HDP) Working Group. Diagnosis, evaluation, and management of the hypertensive disorders of pregnancy. Pregnancy Hypertens 2014. Available at: http://www.pregnancyhypertension.org/article/S22107789(14)00004-X/fulltext. Accessed on February 28, 2014.

4. Ogedegbe G, Pickering T. Principles and techniques of blood pressure measurement. Cardio Clin 2010; 28:571-86.

5. Redman CWG. The placenta, pre-eclampsia and chronic villitis. In: Redman CWG, Sargent IL SP, eds. The human placenta. Oxford: Blackwell Scientific; 1993:433-67.
6. von Dadelszen P, Payne B, Li J, Ansermino JM, Broughton Pipkin F, Côté AM, et al.; PIERS Study Group. Prediction of adverse maternal outcomes in pre-eclampsia: development and validation of the fullPIERS model. Lancet 2011;377(9761):219-27.

7. Payne B, Magee LA, Menzies J, Côté AM, Hutcheon JA, Kyle P, et al.; PIERS Study Group. PIERS proteinuria: relationship with adverse maternal and perinatal outcome. J Obstet Gynaecol Can 2011;33:588-97.

8. Lampinen KH, Rönnback M, Groop PH, Kaaja RJ. Renal and vascular function in women with previous preeclampsia: a comparison of lowand high-degree proteinuria. Kidney Int 2006;70:1818-22.

9. Gruslin A, Lemyre B. Pre-eclampsia: fetal assessment and neonatal outcomes. Best Pract Res Clinl Obstet Gynaecol 2011;25:401-507.

10. Lalor JG, Fawole B, Alfirevic Z, Devane D. Biophysical profile for fetal assessment in high risk pregnancies. Cochrane Database Syst Rev. 2008 Jan 23;(1):CD000038.

11. Kaur S, Picconi JL, Chadha R, Kruger M, Mari G. Biophysical profile in the treatment of intrauterine growth-restricted fetuses who weigh $<1000$ g. Am J Obstet Gynecol 2008;199:264.e1-4.

12. Payne BA, Kyle PM, Lim K, Lisonkova S, Magee LA, Pullar B, et al. An assessment of predictive value of the biophysical profile in women with preeclampsia using data from the full PIERS database. Pregnancy Hypertens 2013;3:166-71.

13. Urquia ML, Ying I, Glazier RH, Berger H, De Souza LR, Ray JG. Serious preeclampsia among different immigrant groups. J Obstet Gynaecol Can 2012;34:348-52.

14. Magee LA, Helewa M, Moutquin JM, von Dadelszen P; Hypertension Guideline Committee; Strategic Training Initiative in Research in the Reproductive Health Sciences (STIRRHS) Scholars. SOGC Clinical Practice Guidelines, No. 206, March 2008. Diagnosis, evaluation, and management of the hypertensive disorders of pregnancy. J Obstet Gynaecol Can 2008;30(3 Suppl 1):S1-S48.

15. American College of Obstetricians and Gynecologists; Task Force on Hypertension in Pregnancy. Hypertension in pregnancy. Report of the American College of Obstetricians and Gynecologists' Task Force on Hypertension in Pregnancy. Obstet Gynecol. 2013;122:1122-31.

16. Brown MA, Lindheimer MD, de Swiet M, Van Assche A, Moutquin JM. The classification and diagnosis of the hypertensive disorders of pregnancy: statement from the International Society for the Study of Hypertension in Pregnancy (ISSHP). Hypertens Pregnancy 2001;20(1):IX-XIV.

17. Why mothers die 2000-2002. The sixth report of the Confidential Enquiries into Maternal Deaths in the United Kingdom. London: RCOG Press; 2004.

18. Rey E, Morin F, Boudreault J, Pilon F, Vincent D, Ouellet D. Blood pressure assessments in different subtypes of hypertensive pregnant women: office versus home patient- or nurse-measured blood pressure. Hypertens Pregnancy 2009;28:168-77.

19. Brown MA, Mangos G, Davis G, Homer C. The natural history of white coat hypertension during pregnancy. BJOG 2005;112:601-6.

20. Magee LA, Ramsay G, von Dadelszen P. What is the role of out-ofoffice BP measurement in hypertensive pregnancy? Hypertens Pregnancy 2008;27:95-101.

21. Saudan P, Brown MA, Buddle ML, Jones M. Does gestational hypertension become pre-eclampsia? Br J Obstet Gynaecol 1998;105:1177-84.

22. Reinders A, Cuckson AC, Lee JT, Shennan AH. An accurate automated blood pressure device for use in pregnancy and pre-eclampsia: the Microlife 3BTO-A. BJOG 2005;112:915-20. 
23. Villar J, Say L, Shennan A, Lindheimer M, Duley L, Conde-Agudelo A, et al. Methodological and technical issues related to the diagnosis, screening, prevention, and treatment of pre-eclampsia and eclampsia. Int J Gynaecol Obstet 2004;85(Suppl 1):S28-S41.

24. Bellomo G, Narducci PL, Rondoni F, Pastorelli G, Stangoni G, Angeli G, et al. Prognostic value of 24-hour blood pressure in pregnancy. JAMA 1999;282:1447-52.

25. Hermida RC, Ayala DE, Iglesias M. Circadian rhythm of blood pressure challenges office values as the "gold standard" in the diagnosis of gestational hypertension. Chronobiol Int 2003;20:135-56.

26. Eguchi, Kazuo O, Akihide O, Takako H, Chikako T, Kayo S, et al. [abstracts of American Society of Hypertension 27th Annual Scientific Meeting and Exposition]. J Clin Hypertens 2012;14(Suppl 1):doi: 10.1111/j.1751-7176.2011.00665.x.

27. Sibai BM. Imitators of severe preeclampsia. Obstet Gynecol 2007;109:956-66.

28. Fesenmeier MF, Coppage KH, Lambers DS, Barton JR, Sibai BM. Acute fatty liver of pregnancy in 3 tertiary care centers. Am J Obstet Gynecol 2005;192:1416-9.

29. Erkan D, Espinosa G, Cervera R. Catastrophic antiphospholipid syndrome: updated diagnostic algorithms. Autoimmun Rev 2010;10:74-9.

30. Martin JN Jr, Bailey AP, Rehberg JF, Owens MT, Keiser SD, May WL. Thrombotic thrombocytopenic purpura in 166 pregnancies: 1955-2006. Am J Obstet Gynecol 2008;199:98-104.

31. Mouthon L, Berezne A, Bussone G, Noel LH, Villiger PM, Guillevin L. Scleroderma renal crisis: a rare but severe complication of systemic sclerosis. Clin Rev Allergy Immunol 2011;40:84-91.
32. Ogge G, Chaiworapongsa T, Romero R, Hussein Y, Kusanovic JP, Yeo L, et al. Placental lesions associated with maternal underperfusion are more frequent in early-onset than in late-onset preeclampsia. J Perinat Med 2011;39:641-52. doi: 10.1515/JPM.2011.098.

33. Akolekar R, Syngelaki A, Poon L, Wright D, Nicolaides KH. Competing risks model in early screening for preeclampsia by biophysical and biochemical markers. Fetal Diagn Ther 2013;33:8-15.

34. Scazzocchio E, Figueras F, Crispi F, Meler E, Masoller N, Mula R, et al. Performance of a first-trimester screening of preeclampsia in a routine care low-risk setting. Am J Obstet Gynecol 2013;208(3):203.e1-203.e10.

35. Roberts D, Dalziel SR. Antenatal corticosteroids for accelerating fetal lung maturation for women at risk of preterm birth. Cochrane Database of Systematic Reviews 2006;(3)CD004454.

36. Stutchfield P, Whitaker R, Russell I; Antenatal Steroids for Term Elective Caesarean Section (ASTECS) Research Team. Antenatal betamethasone and incidence of neonatal respiratory distress after elective caesarean section: pragmatic randomised trial. BMJ 2005;331:662.

37. Roberts D; Royal College of Obstetricians and Gynaecologists. Antenatal corticosteroids to reduce neonatal morbidity and mortality. Green-top Guideline No. 7. London: Royal College of Obstetricians and Gynaecologists; 2010. Available at: http://www.rcog.org.uk/files/ rcog-corp/GTG\%207.pdf. Accessed on February 28, 2014.

38. Shennan AH, Redman C, Cooper C, Milne F. Are most maternal deaths from pre-eclampsia avoidable? Lancet 2012;379(9827):1686-7.

39. Woolf SH, Battista RN, Angerson GM, Logan AG, Eel W. Canadian Task Force on Preventive Health Care. New grades for recommendations from the Canadian Task Force on Preventive Health Care. CMAJ 2003;169:207-8. 


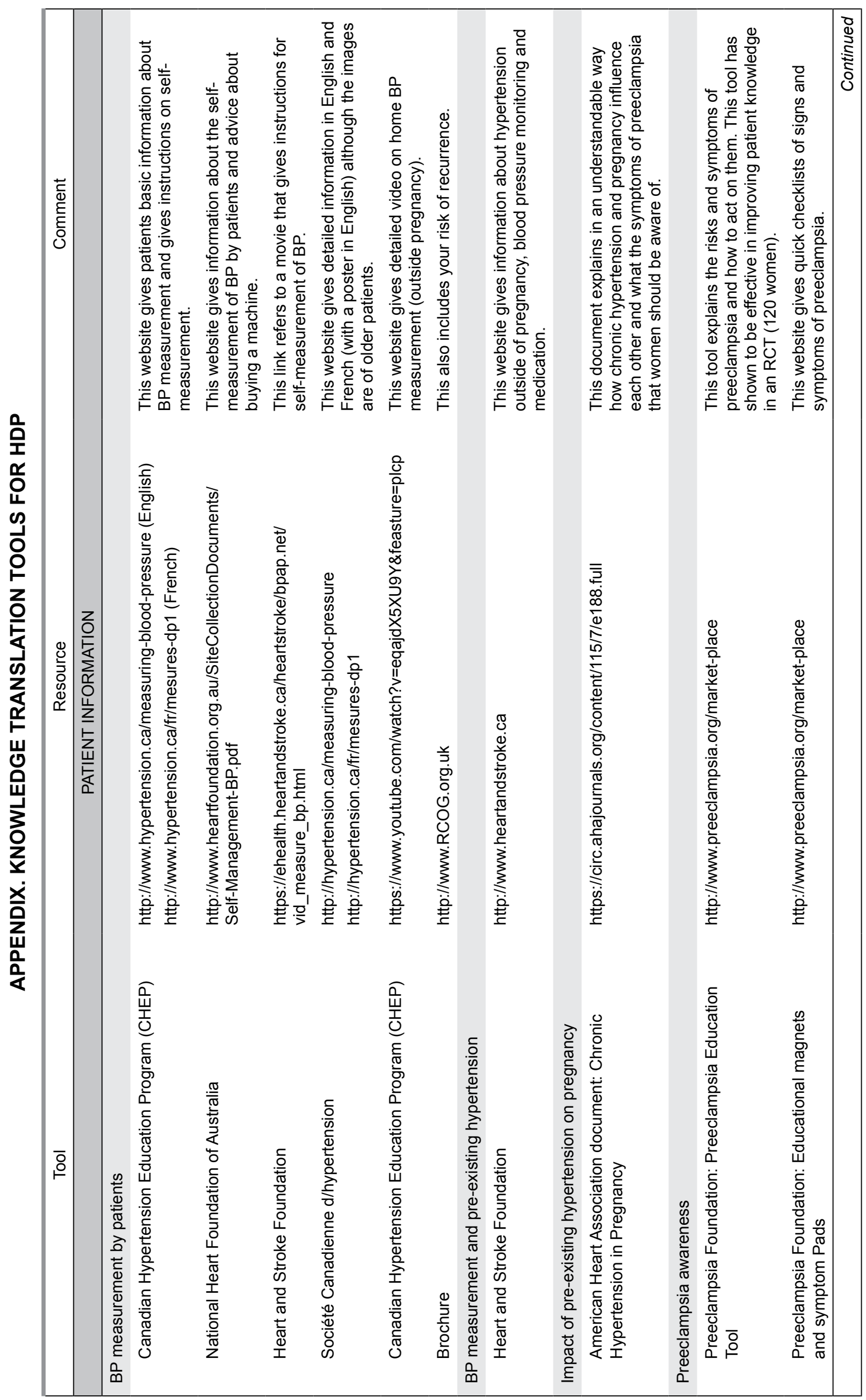




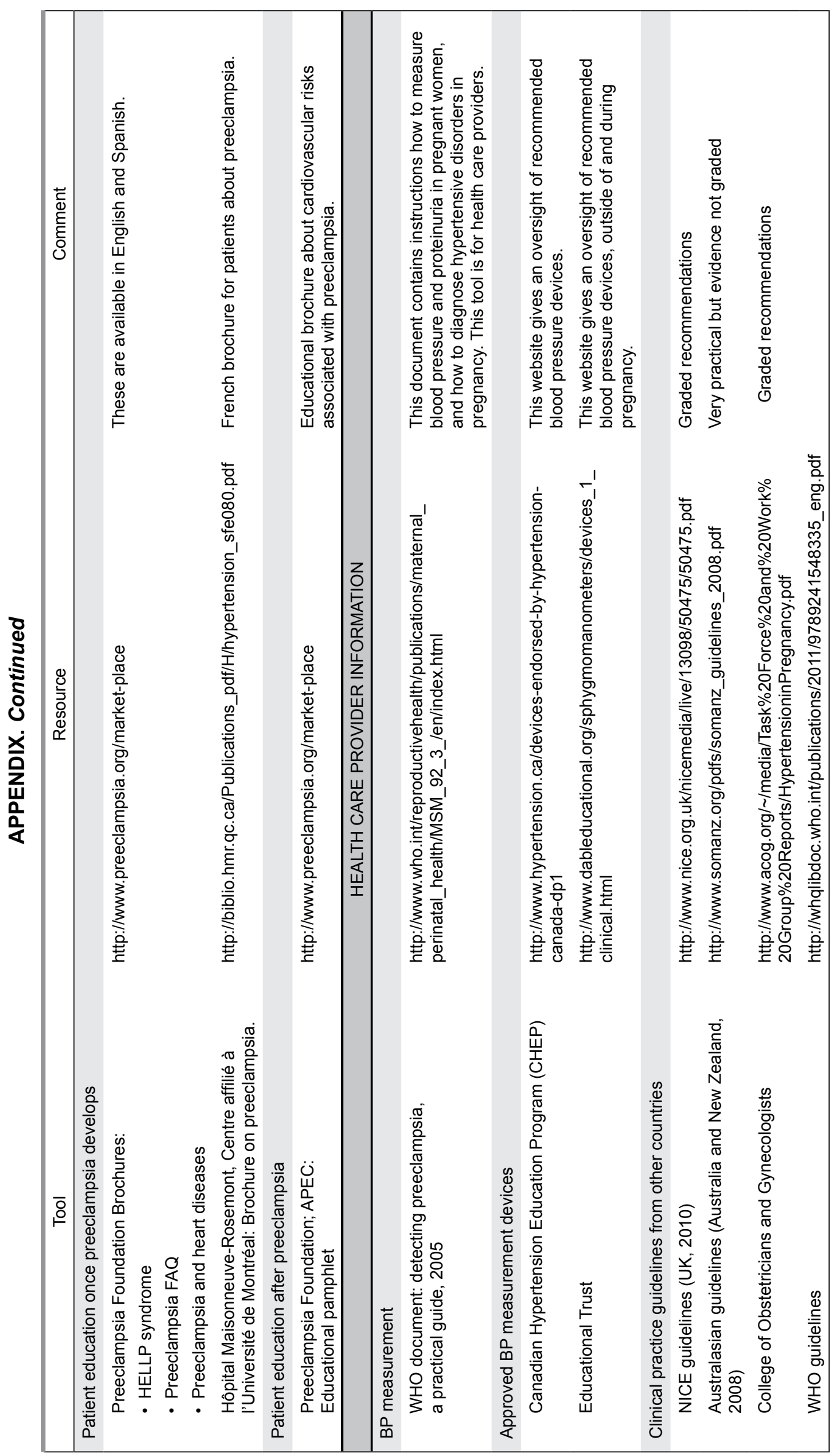

